\title{
En attendant Godot: Waiting for the Funeral of "Schizophrenia" and the Baby Shower of the Psychosis Spectrum
}

\author{
Sinan Guloksuz ${ }^{1,2 *}$ and Jim van Os ${ }^{1,3,4}$ \\ ${ }^{1}$ Department of Psychiatry and Neuropsychology, School for Mental Health and Neuroscience, Maastricht University Medical \\ Center, Maastricht, Netherlands, ${ }^{2}$ Department of Psychiatry, Yale University School of Medicine, New Haven, CT, \\ United States, ${ }^{3}$ Department of Psychiatry, Brain Centre Rudolf Magnus, University Medical Centre Utrecht, Utrecht, \\ Netherlands, ${ }^{4}$ Department of Psychosis Studies, King's College London, King's Health Partners, Institute of Psychiatry, \\ London, United Kingdom
}

Keywords: nosology, taxonomy, classification, DSM, early psychosis, schizophrenia

"Wax on, wax off."

From the movie The Karate Kid, 1984

\section{INTRODUCTION}

OPEN ACCESS

Edited by:

Andrea Raballo,

University of Perugia, Italy

Reviewed by:

Tania Lecomte,

Université de Montréal, Canada

${ }^{*}$ Correspondence:

Sinan Guloksuz

sinan.guloksuz@maastrichtuniversity.nl

Specialty section:

This article was submitted to

Schizophrenia

a section of the journal

Frontiers in Psychiatry

Received: 18 October 2020

Accepted: 03 May 2021

Published: 28 May 2021

Citation:

Guloksuz S and van Os J (2021) En attendant Godot: Waiting for the

Funeral of "Schizophrenia" and the Baby Shower of the Psychosis

Spectrum.

Front. Psychiatry 12:618842. doi: 10.3389/fpsyt.2021.618842
The debate on the concept of schizophrenia is alive and kicking (1) because the concept of schizophrenia is dead and decaying (2). Despite continual demands for reconceptualization proposed by highly influential academics, heated discussions during the revision processes of DSM and ICD, and attacks from every angle, the concept of schizophrenia, as we know it, has managed to "make a goal-line stand" every time. These discussions over decades have failed to go beyond merely stimulating exchanges between scholars that resulted in minor revisions only. We-like the two characters in En attendant Godot-are still waiting for a meaningful action toward reconceptualization that probably will never come. In this brief viewpoint, we will attempt to summarize the shortcomings of the schizophrenia concept and reiterate our understanding of psychosis spectrum disorder-hopefully, once and for all.

\section{THE ILLUSION OF ETIOLOGICAL SPECIFICITY}

The evidence thus far suggests that the etiology of mental disorders consists of multicausal, interdependent, interacting, and non-specific factors contributing to largely shared behavioral, social, and biological mechanisms (3). Schizophrenia is no exception.

Environmental factors, as part of a dynamic network (so-called exposome), associated with schizophrenia, are interdependent and causally and non-causally related to almost all psychiatric phenotypes (4). In the general population, environmental exposures, such as cannabis use and childhood adversity, are not only directly associated with psychotic experiences but also interact with multidimensional psychopathology and family history of affective disorders to increase psychosis expression: the so-called affective pathway to psychosis (5-7).

Genome-wide association studies (GWAS) consistently demonstrate that schizophrenia is genetically correlated with various psychiatric disorders, in particular bipolar disorder $(8,9)$. Similarly, polygenic liability score for schizophrenia is non-specifically associated with subclinical multidimensional phenotypes, including cognitive and affective domains (10-13), as well as broad mental and physical health outcomes in the general population (14). 
Based on the findings showing phenomenological, cognitive, genetic, molecular, and electrophysiological similarities between schizophrenia and bipolar disorder (15), we have argued that schizophrenia, schizoaffective disorder, and bipolar disorder may be different phenotypic presentations of a largely shared pathoetiology with diverse outcome trajectories (2). Multiple sclerosis is a well-known example of substantial phenotypic and clinical heterogeneity that stems from a shared pathoetiology. With the analogy of multiple sclerosis, these different diagnostic categories might be different types of a shared disease process with varying outcomes and phenotypical representations, suggestive of a unitary model of psychosis instead of discrete entities such that: brief psychotic disorder $\sim$ clinically isolated syndrome; bipolar disorder $\sim$ relapsingremitting type; schizoaffective disorder $\sim$ secondary progressive type; schizophrenia $\sim$ primary progressive type. In light of accumulating evidence, we contemplate that psychosis spectrum disorder, a superordinate level category, would likely encompass bipolar disorder, at least in clinical research practice that we already observe in contemporary first episode psychosis studies. However, more transdiagnostic research is needed to confirm this proposition. Furthermore, we wish to clarify that this unitary framework should not be interpreted as against the possibility of distinct subtypes. We envision this unitary approach will set the ideal stage to think beyond the borders of traditional categories in the pursuit of improved taxonomy and may eventually lead to more precise classification.

\section{THE ILLUSION OF DISCRETE ENTITY}

The current taxonomy implies that schizophrenia represents a point of rarity, a discrete disease phenotype with welldefined boundaries. However, converging evidence suggests that psychosis expression, including positive, negative, and cognitive symptoms, represents an etiologically, phenomenologically, and temporally continuous phenotype across the general population, with prevalence rates varying between $5 \%$ (interview-rated) and $8 \%$ (self-report) $(16,17)$.

In the temporal domain, subclinical psychosis expression is associated with subsequent clinical psychotic disorders and nonpsychotic disorders (18) and functional impairment, serving as a general severity indicator for broad psychopathology (17).

Recent findings from GWAS provide support to the liabilitythreshold model, first postulated by Gottesman and Shields more than 50 years ago (19). According to this model, which is fully compatible with the psychosis continuum concept, each individual has quantifiable (environmental and genetic) liability for schizophrenia to varying degrees but develops schizophrenia only when the combined liability exceeds the threshold on the continuum. Conforming to the psychosis continuum model, polygenic risk score for schizophrenia is associated with psychotic experiences in the general population (13). Furthermore, recent evidence lends support for a shared genetic liability between schizophrenia and psychotic experience (20). Environmental factors associated with schizophreniachildhood trauma, cannabis use, urban environment-are likewise strongly associated with psychotic experiences at the population level (21). Furthermore, recent studies suggest that genetic liability for schizophrenia interact with environmental exposure to increase psychosis expression and comorbid psychopathology $(22,23)$.

\section{THE ILLUSION OF PHENOTYPIC SPECIFICITY}

Per definition of current classifications, schizophrenia represents a true distinct disease entity, of which the boundaries are clearly defined. This implication of rarity has reassured the implicit confidence of "schizo"-prism that the origins of the prodrome can logically be traced back using the same operational criteria, with a particular emphasis on positive psychotic subclinical symptoms. This unfounded confidence has led to the birth of the "clinical high risk" concept (24). However, it appears that the predictive performance of the clinical high risk is low, with only around $15 \%$ transitioning to clinical psychosis over a 3 -year period in the help-seeking population (25). The fixation on psychosis-disregarding early expression of non-specific symptoms-comes at the expense of the multidimensional nature of psychopathology. However, it is well-established that non-psychotic psychopathology, such as anxiety, depressed mood, sleep disturbance, motivational impairment, social and neurocognitive alterations, precede early stages of psychotic disorders-so called heterotypic continuity.

In fact, the population-based estimates clearly show that even though the psychosis high-risk state displays a high relative risk for subsequent clinical psychosis outcome, the incidence of clinical psychosis outcome in the general population is largely attributable to non-psychotic mental disorder categories (i.e., mood, anxiety, alcohol, and drug use disorders) (18). These findings show that targeted "clinical high risk" early intervention model based on the schizophrenia concept can yield minimal benefit at the expense of major resource for case-finding, considering the scarcity of the psychosis high-risk state in the population $(24,26)$.

\section{THE ILLUSION OF POOR OUTCOME}

Per definition, schizophrenia is associated with chronicity, deterioration, and poor outcome-as reflected by psychiatrists' perception of schizophrenia: "Persons that turn out 'normal' again a few years later, I am forced to consider that I was mistaken about a schizophrenia early diagnosis" (27); "Good prognosis 'schizophrenia' is not mild schizophrenia, but a different illness" (28). In fact, studies show that a major challenge for improving the outcome of schizophrenia is paradoxically the narrow definition of neo-Kraepelinian schizophrenia, first introduced in DSM-III $(29,30)$.

Furthermore, accumulating evidence shows that early studies conducted mainly in inpatient units and tertiary specialized centers typically collect severity- and chronicity-enriched samples of patients with poor outcome and therefore are subject to systematic selection bias that is known as Berkson's bias 
(31). In this regard, early studies of enriched samples overlook patients with better outcome and those recovered or displayed an improved course of illness and thereby no longer meeting the criteria for schizophrenia diagnosis. Findings from the contemporary studies, particularly those from the follow-up of patients with first episode psychosis in early intervention services, demonstrate that better outcomes are achievable (32). The 10-year follow-up of the Scandinavian TIPS Early Detection in Psychosis Study demonstrated that the recovery percentage was significantly higher in early-detection patients than those in the usual-detection area (30.7 vs. 15.1\%) (33).

\section{THE ILLUSION OF CLINICAL UTILITY}

Psychiatry has disproportionately and erroneously placed too much emphasis on the clinical utility of diagnoses (34). As discussed above, schizophrenia diagnosis does not provide testable theories about the pathoetiology, treatment planning, or management but only "moves the goalpost" with the claim of predicting the course, which in reality comes with the ingrained chronicity and deterioration into the definition of schizophrenia.

Schizophrenia diagnosis has largely been deemed fairly stable and definitive, but mental health care professionals report that inaccurate and controversial diagnosis of schizophrenia in their clinical practice takes place frequently (35). Accordingly, the results of a WHO survey demonstrate that clinicians rate the ease of use and goodness of fit of schizophrenia no higher than other diagnoses, such as depressive and bipolar disorders (36).

\section{SOLUTIONS FOR ILLUSIONS}

There is a growing dissatisfaction with the notion of reifying psychiatric diagnostic categories as discrete entities. Research in search of the origins of schizophrenia has yielded neither actionable nor tangible evidence to improve our understanding. Several frameworks alternative to categorical conceptualization have been introduced particularly for research purposes: the US National Institute of Mental Health (NIMH) initiated Research Domain Criteria (RDoC) and Hierarchical Taxonomy of Psychopathology (HiTOP). Although the multidimensional assessment of schizophrenia was introduced in Section III of DSM -5 as "emerging measures" and the wording was revised slightly as "schizophrenia spectrum disorder," these changes had minimal impact on our use of schizophrenia in clinical practice.

It is clear that we need more-much more-evidence to propose drastic changes in the nosology of mental disorders including schizophrenia. Therefore, instead of a "grand idea," we propose a modest solution to pave the way for better conceptualization and improving clinical practice by emphasizing the importance of clinical characterization over diagnostic reductionism $(37,38)$. To encourage clinicians and researchers to think outside the borders of schizophrenia, we embrace a trans-syndromal framework of mental suffering yet retain an "umbrella" syndrome category (psychosis spectrum disorder) to satisfy clinical practice conventions (2). In fact, we propose the following framework: psychosis spectrum + clinical characterization (38). The use of "psychosis spectrum," while nomothetic, deliberately refers to something so broad and non-specific that it only makes sense if it is accompanied by an idiographic personal characterization. As the word "schizophrenia" has indelible negative connotations and implicit support for discrete entity, renaming is essential to enable seeing without the imaginary boundaries of current schizophrenia concept (39).

\section{META-SOLUTIONS FOR DENIAL: FROM REPUDIATION TO TAKING RESPONSIBILITY}

It is clear that the time for the funeral of schizophrenia was yesterday; nevertheless, we remain in the denial stage. Why is this so?

About three decades ago, Mary Boyle wrote her seminal work on schizophrenia as a "scientific delusion" (40). Many authors have since delivered similar cogent, scientific, clinical, ethical, and public health arguments for abandoning the schizophrenia concept (41-45) - yet nothing has changed. It is well-known that a switch in terminology can result in a disease being perceived as more serious and more likely to be a rare condition (46). Therefore, in medicine, changes in terminology are readily applied in response to social or ethical demands. Erectile Dysfunction, Myocardial Infarction, Alzheimer's disease and Down's syndrome are but a few examples. Such changes reflect the advent of the "moral era" of medicine and health care (47), in which the focus is not on narrow medical outcomes per se but on the degree to which they add value to highly personal life goals of the patient. Patients, professionals, and institutions therefore should learn to work together to "co-create" a terminology to suit the needs of the individual and society within the space of the inevitable scientific uncertainty surrounding the condition in question. Arguably, no area of medicine presents with more moral dilemmas as the practice of calling mental variation "things"-for example, "schizophrenia"-particularly, if accompanied by scientifically unfounded conviction that the "thing" is a nosological entity and is embedded exclusively in the brain. The bearer of an experience that falls within this nosological entity, for example, a person hearing voices, likely will have difficulties making himself "heard," because the mental health professional-and society in line with himhears a symptom of a distinct brain disease. This phenomenon is called "epistemic injustice" and arguably represents one of the most important dilemmas to solve, should psychiatry wish to enter the moral era of medicine (48). Put simply, premature conclusions based on inconclusive science have real consequences that can result in epistemic injustice, and the use of the term "schizophrenia" has all the hallmarks of this. The degree to which psychiatry remains tone deaf to the issue of epistemic injustice inherent to schizo-labeling, matches with the evident loss of societal support for psychiatry as a science (49). Psychiatry, unlike oncology for example, receives cogent and well-organized critical feedback from many sources, including Mad in America and the Hearing Voices Movement. Instead of ignoring these sources of critical review, psychiatry could actively engage with them and co-create solutions, particularly 
for pressing problems like the language and the concepts we use to describe mental variation.

In conclusion, there is ample reason for psychiatry to consider the issue of management of diversity with the gravity it deserves. Instead of letting the field become increasingly imprudent to diversity, we can choose innovation that befits the moral era of medicine, and grow out of our self-imposed state of nonresponsiveness to embrace diversity in a fashion that fits science and avoids epistemic injustice.

\section{REFERENCES}

1. Comparelli A, Raballo A, Pompili M, Galderisi S. Beyond the transnosographic emphasis on psychosis: nosological perspectives on schizophrenia and its prevention. Front Psychiatry. (2019) 10:666. doi: 10.3389/fpsyt.2019.00666

2. Guloksuz S, Van Os J. The slow death of the concept of schizophrenia and the painful birth of the psychosis spectrum. Psychol Med. (2018) 48:22944. doi: 10.1017/S0033291717001775

3. Hollander JA, Cory-Slechta DA, Jacka FN, Szabo ST, Guilarte TR, Bilbo SD, et al. Beyond the looking glass: recent advances in understanding the impact of environmental exposures on neuropsychiatric disease. Neuropsychopharmacology. (2020) 45:1086-96. doi: 10.1038/s41386-020-0648-5

4. Guloksuz S, Rutten BP, Pries L-K, Ten Have M, de Graaf R, van Dorsselaer $\mathrm{S}$, et al. The complexities of evaluating the exposome in psychiatry: a datadriven illustration of challenges and some propositions for amendments. Schizophrenia Bull. (2018) 44:1175-9. doi: 10.1093/schbul/sby118

5. Guloksuz S, van Nierop $M$, Lieb $R$, van Winkel $R$, Wittchen $\mathrm{H}-\mathrm{U}$, van Os J. Evidence that the presence of psychosis in nonpsychotic disorder is environment-dependent and mediated by severity of non-psychotic psychopathology. Psychol Med. (2015) 45:2389-401. doi: 10.1017/S0033291715000380

6. Pries L-K, Guloksuz S, Ten Have M, De Graaf R, Van Dorsselaer S, Gunther N, et al. Evidence that environmental and familial risks for psychosis additively impact a multidimensional subthreshold psychosis syndrome. Schizophr Bull. (2018) 44:710-9. doi: 10.1093/schbul/sby051

7. Radhakrishnan R, Guloksuz S, Ten Have M, de Graaf R, van Dorsselaer S, Gunther N, et al. Interaction between environmental and familial affective risk impacts psychosis admixture in states of affective dysregulation. Psychol Med. (2018) 49:1879-89. doi: 10.1017/S0033291718002635

8. Mullins N, Forstner AJ, O'Connell KS, Coombes B, Coleman JRI, Qiao Z, et al. Genome-wide association study of over 40,000 bipolar disorder cases provides novel biological insights. medRxiv [Preprint]. (2020). doi: 10.1101/2020.09.17.20187054

9. Ripke S, Walters JT, O’Donovan MC. Mapping genomic loci prioritises genes and implicates synaptic biology in schizophrenia. medRxiv [Preprint]. (2020). doi: 10.1101/2020.09.12.20192922

10. van Os J, Van Der Steen Y, Islam MA, Guloksuz S, Rutten B, Simons C, et al. Evidence that polygenic risk for psychotic disorder is expressed in the domain of neurodevelopment, emotion regulation and attribution of salience. Psychol Med. (2017) 47:2421-37. doi: 10.1017/S0033291717000915

11. van Os J, Pries L-K, Delespaul P, Kenis G, Luykx JJ, Lin BD, et al. Replicated evidence that endophenotypic expression of schizophrenia polygenic risk is greater in healthy siblings of patients compared to controls, suggesting geneenvironment interaction. The EUGEI study. Psychol Med. (2020) 50:188497. doi: 10.1017/S003329171900196X

12. Richardson TG, Harrison S, Hemani G, Smith GD. An atlas of polygenic risk score associations to highlight putative causal relationships across the human phenome. Elife. (2019) 8:e43657. doi: 10.7554/eLife.43657

13. Mistry S, Harrison JR, Smith DJ, Escott-Price V, Zammit S. The use of polygenic risk scores to identify phenotypes associated with genetic risk of schizophrenia: systematic review. Schizophr Res. (2018) 197:28. doi: 10.1016/j.schres.2017.10.037

\section{AUTHOR CONTRIBUTIONS}

SG and JO contributed to the article and approved the submitted version.

\section{FUNDING}

SG and JO are supported by the Ophelia research project, ZonMw Grant No. 636340001.

14. Pries L-K, van Os J, Ten Have M, de Graaf R, van Dorsselaer S, Bak M, et al. Association of recent stressful life events with mental and physical health in the context of genomic and exposomic liability for schizophrenia. JAMA Psychiatry. (2020) 77:1296-304. doi: 10.1001/jamapsychiatry.2020.2304

15. Clementz BA, Trotti RL, Pearlson GD, Keshavan MS, Gershon ES, Keedy SK, et al. Testing psychosis phenotypes from bipolar-schizophrenia network for intermediate phenotypes for clinical application: biotype characteristics and targets. Biol Psychiatry Cogn Neurosci Neuroimaging. (2020) 5:80818. doi: 10.1016/j.bpsc.2020.03.011

16. Mennigen E, Bearden CE. Psychosis risk and development: what do we know from population-based studies? Biol Psychiatry. (2019) 88:31525. doi: 10.1016/j.biopsych.2019.12.014

17. van Os J, Reininghaus U. Psychosis as a transdiagnostic and extended phenotype in the general population. World Psychiatry. (2016) 15:11824. doi: 10.1002/wps. 20310

18. Guloksuz S, Pries LK, ten Have M, de Graaf R, van Dorsselaer S, Klingenberg B, et al. Association of preceding psychosis risk states and nonpsychotic mental disorders with incidence of clinical psychosis in the general population: a prospective study in the NEMESIS-2 cohort. World Psychiatry. (2020) 19:199-205. doi: 10.1002/wps.20755

19. Gottesman II, Shields J. A polygenic theory of schizophrenia. Proc Natl Acad Sci USA. (1967) 58:199-205. doi: 10.1073/pnas.58.1.199

20. Legge SE, Jones HJ, Kendall KM, Pardiñas AF, Menzies G, Bracher-Smith $\mathrm{M}$, et al. Association of genetic liability to psychotic experiences with neuropsychotic disorders and traits. JAMA Psychiatry. (2019) 76:125665. doi: 10.1001/jamapsychiatry.2019.2508

21. Van Os J, Kenis G, Rutten BP. The environment and schizophrenia. Nature. (2010) 468:203-12. doi: 10.1038/nature09563

22. Guloksuz S, Pries LK, Delespaul P, Kenis G, Luykx JJ, Lin BD, et al. Examining the independent and joint effects of molecular genetic liability and environmental exposures in schizophrenia: results from the EUGEI study. World Psychiatry. (2019) 18:173-82. doi: 10.1002/wps. 20629

23. Pries L-K, Ferro GAD, van Os J, Delespaul P, Kenis G, Lin BD, et al. Examining the independent and joint effects of genomic and exposomic liabilities for schizophrenia across the psychosis spectrum. Epidemiology Psychiatr Sci. (2020) 29:e182. doi: 10.1017/S2045796020000943

24. van Os J, Guloksuz S. A critique of the "ultra-high risk" and "transition" paradigm. World Psychiatry. (2017) 16:200-6. doi: 10.1002/wps.20423

25. Schmidt SJ, Schultze-Lutter F, Schimmelmann BG, Maric NP, Salokangas $\mathrm{R}$, Riecher-Rössler A, et al. EPA guidance on the early intervention in clinical high risk states of psychoses. Euro Psychiatry. (2015) 30:388404. doi: 10.1016/j.eurpsy.2015.01.013

26. Guloksuz S, van Os J. Need for evidence-based early intervention programmes: a public health perspective. Evid Based Ment Health. (2018) 21:128-30. doi: 10.1136/ebmental-2018-300030

27. Benoit L, Moro MR, Falissard B, Henckes N. Psychosis risk research versus daily prognosis uncertainties: a qualitative study of French youth psychiatrists' attitudes toward predictive practices. PLoS ONE. (2017) 12:e0179849. doi: 10.1371/journal.pone.017 9849

28. Robins E, Guze SB. Establishment of diagnostic validity in psychiatric illness: its application to schizophrenia. Am J Psychiatry. (1970) 126:9837. doi: 10.1176/ajp.126.7.983 
29. McGlashan TH. A selective review of recent North American longterm followup studies of schizophrenia. Schizophr Bull. (1988) 14:51542. doi: 10.1093/schbul/14.4.515

30. Bromet EJ, Naz B, Fochtmann LJ, Carlson GA, Tanenberg-Karant M. Longterm diagnostic stability and outcome in recent first-episode cohort studies of schizophrenia. Schizophr Bull. (2005) 31:639-49. doi: 10.1093/schbul/sbi030

31. Maric N, Myin-Germeys I, Delespaul P, de Graaf R, Vollebergh W, and Van Os J. Is our concept of schizophrenia influenced by Berkson's bias? Soc Psychiatry Psychiatr Epidemiol. (2004) 39:600-5. doi: 10.1007/s00127-004-0803-Z

32. Correll CU, Galling B, Pawar A, Krivko A, Bonetto C, Ruggeri M, et al. Comparison of early intervention services vs treatment as usual for earlyphase psychosis: a systematic review, meta-analysis, and meta-regression. JAMA Psychiatry. (2018) 75:555-65. doi: 10.1001/jamapsychiatry.2018.0623

33. Hegelstad WV, Larsen TK, Auestad B, Evensen J, Haahr U, Joa I, et al. Long-term follow-up of the TIPS early detection in psychosis study: effects on 10-year outcome. Am J Psychiatry. (2012) 169:37480. doi: 10.1176/appi.ajp.2011.11030459

34. Maj M. Why the clinical utility of diagnostic categories in psychiatry is intrinsically limited and how we can use new approaches to complement them. World Psychiatry. (2018) 17:121-2. doi: 10.1002/wps.20512

35. Bitan DT, Giron AG, Alon G, Mendlovic S, Bloch Y, Segev A. Attitudes of mental health clinicians toward perceived inaccuracy of a schizophrenia diagnosis in routine clinical practice. BMC Psychiatry. (2018) 18:317. doi: 10.1186/s12888-018-1897-2

36. Reed GM, Correia JM, Esparza P, Saxena S, Maj M. The WPA-WHO global survey of psychiatrists' attitudes towards mental disorders classification. World Psychiatry. (2011) 10:118-31. doi: 10.1002/j.2051-5545.2011.tb00034.x

37. van Os J, Guloksuz S, Vijn TW, Hafkenscheid A, Delespaul P. The evidencebased group-level symptom-reduction model as the organizing principle for mental health care: time for change? World Psychiatry. (2019) 18:8896. doi: 10.1002/wps.20609

38. Guloksuz S, van Os J. Strangelove, or how we learned to stop worrying and love uncertainty. World Psychiatry. (2020) 19:395-6. doi: 10.1002/wps.20794

39. Guloksuz S, van Os J. Renaming schizophrenia: $5 \times 5$. Epidemiology Psychiatr Sci. (2019) 28:254-7. doi: 10.1017/S2045796018000586

40. Boyle M. Schizophrenia: A Scientific Delusion? London: Routledge (1990).
41. van Praag HM. About the impossible concept of schizophrenia. Compr Psychiatry. (1976) 17:481-97. doi: 10.1016/0010-440X(76)90031-6

42. Bentall RP, Jackson HF, Pilgrim D. Abandoning the concept of 'schizophrenia': some implications of validity arguments for psychological research into psychotic phenomena. $\mathrm{Br} J$ Clin Psychol. (1988) 27:303-24. doi: 10.1111/j.2044-8260.1988.tb00 795.x

43. Lasalvia A, Penta E, Sartorius N, Henderson S. Should the label "schizophrenia" be abandoned? Schizophr Res. (2015) 162:276-84. doi: 10.1016/j.schres.2015.01.031

44. Moncrieff J, Middleton H. Schizophrenia: a critical psychiatry perspective. Curr Opin Psychiatry. (2015) 28:264-8. doi: 10.1097/YCO.000000000000 0151

45. Geekie J, Read J. Making Sense of Madness: Contesting the Meaning of Schizophrenia. London: Routledge (2009). doi: 10.4324/9780203878422

46. Young ME, Norman GR, Humphreys KR. The role of medical language in changing public perceptions of illness. PLoS ONE. (2008) 3:e3875. doi: 10.1371/journal.pone. 0003875

47. Berwick DM. Era 3 for medicine and health care. JAMA. (2016) 315:1329_ 30. doi: 10.1001/jama.2016.1509

48. Crichton P, Carel H, Kidd IJ. Epistemic injustice in psychiatry. B J Psych Bull. (2017) 41:65-70. doi: 10.1192/pb.bp.115.050682

49. Braslow JT, Brekke JS, Levenson J. Psychiatry's myopia-reclaiming the social, cultural, and psychological in the psychiatric gaze. JAMA Psychiatry. (2020) 78:349-350. doi: 10.1001/jamapsychiatry.2020.2722

Conflict of Interest: The authors declare that the research was conducted in the absence of any commercial or financial relationships that could be construed as a potential conflict of interest.

Copyright (c) 2021 Guloksuz and van Os. This is an open-access article distributed under the terms of the Creative Commons Attribution License (CC BY). The use, distribution or reproduction in other forums is permitted, provided the original author(s) and the copyright owner(s) are credited and that the original publication in this journal is cited, in accordance with accepted academic practice. No use, distribution or reproduction is permitted which does not comply with these terms. 